\title{
The adverse selection problem in imperfectly competitive credit markets
}

\author{
Ville Mälkönen \\ VATT (Government Institute for Economic Research) \\ and \\ Timo Vesala \\ Bank of Finland, University of Helsinki, RUESG and HECER
}

Discussion Paper No. 112

August 2006

ISSN 1795-0562

HECER - Helsinki Center of Economic Research, P.O. Box 17 (Arkadiankatu 7), FI-00014 University of Helsinki, FINLAND, Tel +358-9-191-28780, Fax +358-9-191-28781,

E-mail info-hecer@helsinki.fi, Internet www.hecer.fi 


\title{
The adverse selection problem in imperfectly competitive credit markets*
}

\begin{abstract}
We study the adverse selection problem in imperfectly competitive credit markets and illustrate the circumstances where a separating equilibrium emerges, even without collateral. The borrowers are heterogeneous in their preferences concerning the banks. Separation obtains in market segments where the 'high risk' borrowers receive credit from their preferred bank. The 'low risk' borrowers choose the ex-ante less-preferred bank that offers loan contracts with lower interest rates. The availability of credit will be maximized under an intermediate level of competition, a prediction that is supported by recent empirical evidence.
\end{abstract}

JEL Classification: D43, D82, G21, L13

Keywords: Asymmetric information, credit rationing, bank differentiation

Ville Mälkönen

VATT

P.O. BOX 1279

FI-00101 Helsinki

FINLAND

e-mail: ville.malkonen@vatt.fi
Timo Vesala

Department of Economics

University of Helsinki

P.O. BOX 17 (Arkadiankatu 7)

FI-00014 University of Helsinki

FINLAND

e-mail: tvesala@mappi.helsinki.fi

* The views expressed are those of the authors and do not necessarily reflect the views of the Bank of Finland or VATT. The authors are grateful to Esa Jokivuolle, Tuomas Takalo and Jouko Vilmunen for valuable comments and suggestions. They also thank the participants in various research seminars at the Bank of Finland, RUESG and GSF for helpful comments and discussions. Vesala wishes to thank RUESG and Yrjö Jahnsson Foundation for financial support, and the Research Unit of the Bank of Finland for hospitality. 


\section{Introduction}

Asymmetric information in credit markets generates an adverse selection equilibrium, if the Walrasian loan price based on the average risk of the borrowers is too high to induce the participation of low risk customers. ${ }^{1}$ The equilibrium is inefficient, as it increases the credit risk in banks' portfolio and high interest rates ration economically viable projects from credit. To mitigate adverse selection lenders can employ screening instruments, such as collateral, which might induce separating equilibrium in the market. ${ }^{2}$ These lending practices are, however, socially wasteful, because collateral is more valuable to the borrower than to the lender. Besanko and Thakor (1987) show that the use of collateral as a sorting instrument depends on the particularities of the markets studied. Under perfect competition collateral is a meaningful sorting device, but optimal credit policy under monopolistic competition involves zero collateral, as the bank rather sorts the borrowers using price rationing. Villas-Boas and Schmidt-Mohr (1999) investigate oligopolist credit markets and derive a similar result where higher degree of competition mitigates adverse selection through increased screening. Although increased screening mitigates adverse selection, Villas-Boas and Schmidt-Mohr argue that the social cost of posting collateral implies lower welfare than in the case of less competitive markets.

The objective of this paper is to further examine the adverse selection problem in imperfectly competitive credit markets where borrowers have no collaterizable wealth outside the borrowing firms' assets. This situation is especially relevant when borrowers apply for loans for launching new businesses. Contrary to the existing papers on adverse selection in the credit market under imperfect competition, we show that a separating outcome may arise from the underlying structure of the credit market where the borrowers have an initial preference to one bank over the other. This implies that separating equilibrium can be implemented without collateral or price rationing. The result, however, requires that the intensity of competition in the credit market is neither very high nor too low, because the supply of credit is maximized at some intermediate level of bank competition.

The idea that neither perfect nor very modest competition in the credit market is conducive to high supply of credit is in line with market evidence. For instance, Bonaccorsi di Patti and Dell'Ariccia (2004) find a 'bell-shaped' relationship between bank competition and firm

\footnotetext{
${ }^{1}$ See Stiglitz and Weiss (1981), which draws on the 'lemons market outcome' derived by Akerlof (1970). Other early models on adverse selection and credit rationing include Jaffee and Russel (1976) and Keeton (1979). For a review, see Clemenz and Ritthaler (1992)

${ }^{2}$ Bester $(1985,1987)$ characterizes how banks can implement a perfectly sorting competitive equilibrium by offering menus of loan contracts with different combinations of interest rate and collateral requirement.
} 
creation. Since the availability of credit is a necessary precondition to launching new economic activities, where collateral constraints often bind, the result resembles the one derived in this paper. Bonaccorsi di Patti and Dell'Ariccia also report that the pattern is pronounced in informational opaque industries; i.e. in sectors where the adverse selection problem is the most likely to arise. One possible interpretation of our analysis is that the adverse selection problem can severely limit the feasibility of 'transaction based' lending under very competitive or highly monopolized market conditions. Our results may therefore help understand recent evidence (e.g. Elsas, 2005) that 'relationship based' lending tends to be most widely used when the competition in the credit market is either very intense or rather low.

We consider a credit market involving an imperfectly competitive banking sector and customers who prefer one bank over the other, so that for conducting business with the less preferred bank induces a disutility for the borrower. ${ }^{3}$ We prove the existence of a separating equilibrium where the preferred bank serves only the high risk customers while the low risk borrowers receive finance from the ex-ante non-preferred bank. ${ }^{4}$ The intuition why the separating equilibrium is feasible resembles the reason why different collateral requirements can induce separation. Since borrowers are protected by limited liability, the 'high risk high yield' customers rather accept higher interest rates from the preferred bank than pay the cost for visiting the less preferred one. ${ }^{5}$ The 'low risk - low yield' borrowers, in turn, are more sensitive to interest rates and therefore more likely accept an offer with lower interest rates. Consequently, the non-preferred bank can capture the low risk customers, insofar as it can feasibly internalize the cost the borrowers incur. Compared with the perfect competition benchmark, imperfect competition improves market efficiency as it prevents the low risk customers from being rationed.

As is usual in spatial models of imperfect competition, the cost of visiting banks can be used as proxy for the degree of competition in the credit market. This indicates that the banks should have a certain degree of market power to ensure that the separating equilibrium exists. To show this, we derive a threshold for the degree of competition where the sepa-

\footnotetext{
${ }^{3}$ The interpretation of the cost reflects a wide array of dimensions, ranging from geographical preferences to suitability of available accounts and other financial services. Alternatively, each location can be thought as a submarket where one bank holds a position as a preferred supplier of finance.

${ }^{4}$ Ex-ante non-preferred bank refers to a bank the borrower would not choose, if she received an identical quote from another bank.

${ }^{5}$ Even though the pecuniary magnitude of the 'travel cost' of visiting the less-preferred bank may not be comparable to collateral requirements, Kim, Kliger and Vale (2003) assert that costs of this kind, e.g. switching costs, can be substantial and they significantly reduce the contestability of the banking sector.
} 
rating equilibrium becomes feasible. Beyond this limit the availability of credit to the low risk customers gradually increases as the intensity of competition decreases. The separating outcome is thus feasible in the market segments where the cost of visiting the non-preferred bank is sufficiently large, so that only low risk borrowers have an incentive to accept the quote with a lower rate. This outcome holds insofar as the banks can reduce the interest rates to compensate the low risk borrowers for the loss they incur applying loans from the initially less preferred bank. Hence, as the monopoly power of the banks increases above a certain level, the relative share of the separating market segments decreases. The relationship between competition and borrower separation indicates that there is a unique level of competition for which the overall availability of credit is at the highest. This also turns out to be the welfare maximizing market structure.

The results derived in this paper resemble both Besanko and Thakor (1987) and VillasBoas and Schmidt-Mohr (1999) where screening is more valuable in a competitive market environment and less meaningful in imperfectly competitive markets. However, the existence of a separating equilibrium without explicit screening activities is obviously a qualification to the existing results. Our model can also be used to assess banks' risk taking behavior under different competitive environments. The property that there is a welfare maximizing market structure which minimizes credit rationing in the market also minimizes the average default risk in the banks' portfolio; i.e. the degree of competition and risk taking are nonmonotonously related. The result thus contradicts the usual argument that banks tend to choose riskier portfolio strategies when the competition increases (e.g. Keeley, 1990; Besanko and Thakor 1987, 1993; Boot and Greenbaum, 1993; Edwards and Mishkin, 1995). ${ }^{6}$ In the customer screening literature Broecker (1990), Nakamura (1993) and Riordan (1993) identify winner's curse type distortions of competition. The broad idea is that when the banks' screening technologies are imperfectly correlated, the likelihood of a poor loan applicant getting finance increases as the number of banks operating in the market is higher induces too much finance as opposed to credit rationing ${ }^{7}$. Finally, our study relates to the literature on

\footnotetext{
${ }^{6}$ Carletti and Hartmann (2003) survey the literature and conclude that the relationship between competition and risk taking is not necessarily robust. In the moral hazard literature,for instance, there are models showing that also the reverse can be true. Caminal and Matutes (2002) show that a monopoly bank might grant larger loans than competitive banks, which leads to a riskier portfolio, if the risks are non-diversifiable.

${ }^{7}$ A similar overlending result is obtained by DeMeza and Webb (1987) in a variant of the competitive adverse selection model where high risk borrowers are poorer customers also in a sense that they have lower expected returns.
} 
customer poaching (e.g. Chen, 1997; Fudenberg and Tirole, 2000). ${ }^{8}$ The conventional poaching story is that firms may offer discounts to their competitor's customers if this 'stolen' business can in later periods be secured by establishing switching cost barriers. In our model poaching emerges as an equilibrium strategy in situations where the banks fail to sort borrowers in their captive market segments, but the borrowers' heterogeneous preferences toward the banks allow the banks to 'cherry-pick' the low risk customers from the rival's captive markets.

The rest of the paper is organized as follows. Section 2 outlines the basic setup of the model. The credit market equilibria are derived in Section 3. Section 4 discusses the relationship between the bank competition and the availability of credit. Section 5 concludes.

\section{Preliminaries}

Consider a credit market with two banks $A$ and $B$. The borrowers are endowed with a technology which combined with capital yields a stochastic income. Banks offer standard debt contracts to borrowers. The amount of capital required to start a project is normalized to unity and the borrowers' debt service obligation to bank $I$ is denoted by $R_{I}(I=A, B)$. There is a perfectly elastic supply of funds where the banks can borrow at rate $\bar{R}$.

It is common knowledge that a fraction $\lambda$ of the borrowers' projects have a low success probability $p_{L}$. The complementary fraction $1-\lambda$ are borrowers with high success probability $p_{H}$. The value of the output generated by an $L$-type borrower is $q_{L}$. The value of a project with higher success probability ( $H$-type) is $q_{H}$. If the project fails, it produces nothing regardless of the type of the borrower. Following Stiglitz and Weiss $(1981)^{9}$ we assume that the expected values of the outputs are such that

$$
Q_{L}=p_{L} q_{L}=Q_{H}=p_{H} q_{H} \equiv Q
$$

indicating that the $H$-type is better than the $L$-type according to the second-order stochastic dominance. Moreover, we assume that $Q>\bar{R}$, so that the projects obtain positive 'social' NPV.

\footnotetext{
${ }^{8}$ Bouckaert and Degryse (2006) analyze poaching and entry in credit markets where incumbent banks have an information advantage over the entrants. In their model poaching occurs if the adverse selection problem is not too harsh or the incumbent bank shares information with the entrant.

${ }^{9}$ Our justification for relating the Stiglitz-Weiss assumption to debt financing is that our purpose is not to discuss optimal contracts (cf. De Meza and Webb, 1987) but to elaborate the consequences of the classical adverse selection problem, given that the form of the financial contract is standard debt, which is in practice commonly used in any bank lending business.
} 
Since the banks cannot learn the types of the borrowers ex-ante, these assumptions readily imply that in a pooling equilibrium where both types of borrowers apply for loans, the break even rate for the banks is

$$
\hat{R}=\frac{\bar{R}}{\lambda p_{L}+(1-\lambda) p_{H}} .
$$

This condition implies that the credit market is subject to an adverse selection problem when $\hat{R}>q_{H}$, because there is no feasible loan rate such that both the bank would break even and each borrower would accept the same loan contract. The credit market thus exists only for $L$-types if the interest rate $R$ satisfies $q_{L} \geq R \geq \hat{R}$. This outcome is inefficient in a sense that some potentially gainful trade fails to occur.

Following the spatial competition models, first introduced by Hotelling (1929), we assume that the banks operate in a market with a continuum of borrowers distributed uniformly on a line with length $l$. The banks are spatially differentiated so that they are located at the two opposite ends of the line - bank $A$ at location 0 and bank $B$ at location $l$. The borrowers are randomly distributed over the line so that each location is occupied by an $L$-type with probability $\lambda$.

The borrowers have a subjective preference toward accepting an offer from either bank $A$ or bank $B$. Customers closer to location 0 prefer bank $A$ while customers closer $l$ prefer bank $B$. Customers located in $l / 2$ are indifferent between the two banks. Visiting a non-preferred bank a borrower incurs a cost which equals the customers' distance from the centre measured by the index $x$. To economize in notation, we assume that the cost the borrowers incur for borrowing from the less preferred bank is linear and increasing with unit slope in distance between the center of the line and the borrower. Thus, $x$ represents the location of a particular customer and the cost of visiting the banks. The preferred bank can always be approached without any costs. The assumption $Q>\bar{R}$ guarantees that trade is feasible between any loan applicant and the ex ante preferred bank. The customers in bank $A$ 's ( $B$ 's) 'captive' market segment thus face a cost $x_{A} \in[0, l / 2]\left(x_{B} \in[0, l / 2]\right)$, should they accept the offer quoted by the non-preferred bank.

In what follows we use the parameter $l$ as a proxy for the degree of competition in the market. Since this is the distance between the banks, it can be linked to more traditional models of spatial competition, such as Salop (1979), where the distance between the sellers decreases as the number of active firms increases. The assumption that the borrowers incur a cost visiting only the more distant bank is obviously a simplification. We, however, note 
that the qualitative results of the paper can be derived in a conventional spatial models such as Hotelling (1929) and Salop (1979). ${ }^{10}$ Figure 1 illustrates the spatial setup of the model.

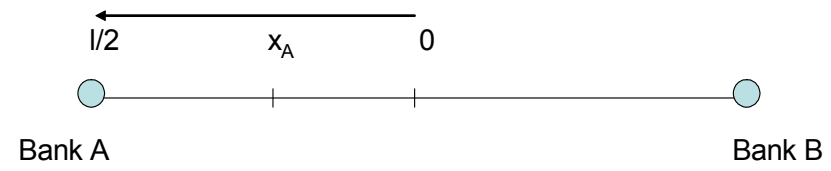

Figure 1

We assume the banks can observe borrowers' exact locations. Our justification for this assumption is that the banks can usually gather some information, for instance, about the clients' demand for different financial services. If we adopt the geographical interpretation of the spatial model, it is obvious that geographical locations of borrowers can easily be assessed on behalf of the banks. As the loan contract offers are typically delivered to each loan applicant separately, these assumptions imply that the banks can effectively price discriminate the borrowers across locations.

\section{Equilibrium in Credit markets}

This section characterizes the equilibrium in the credit markets. The analysis proceeds in three steps. At first, we derive the market segments where separating outcome can be supported as an equilibrium. Second, we derive the adverse selection outcomes in locations where only the $L$-type borrowers will be financed. Finally, we illustrate how the competitiveness of the credit market affects the availability of finance for the $H$-type borrowers.

\subsection{Separating equilibrium}

We proceed under the conjecture that separation is feasible only if $x_{i} \in\left[\underline{x}_{i}, \bar{x}_{i}\right]$, and then show that this conjecture is fulfilled in equilibrium. A separating equilibrium within these locations is such that the preferred bank offers loan contracts only acceptable to the $L$-types in this market segment while the non-preferred bank is able to serve the $H$-type borrowers.

Consider bank $A$ as the preferred bank. When offering loan contracts to borrowers in locations $x_{A} \in\left[\underline{x}_{A}, \bar{x}_{A}\right]$, bank $A$ 's optimization program is

\footnotetext{
${ }^{10}$ This would, however, increase the notation and conditions ensuring the existence of the relevant equilibria without adding any insight to the main results.
} 


$$
\begin{gathered}
\max _{R_{A}} p_{L} R_{A}-\bar{R} \\
\text { s.t. } R_{A} \geq \frac{\bar{R}}{p_{L}} \\
p_{L}\left(q_{L}-R_{A}\right) \geq 0 \\
p_{L}\left(q_{L}-R_{A}\right) \geq p_{L}\left(q_{L}-R_{B}\right)-x_{A},
\end{gathered}
$$

where $x_{A}$ is the cost the borrower located at $x_{A}$ incurs for visiting Bank $B$. The existence of a separating equilibrium requires that although $H$-type borrower must pay the cost, she rather accepts the offer from bank $B$. The problem of bank $B$ is therefore the following

$$
\begin{gathered}
\max _{R_{B}} p_{H} R_{B}-\bar{R} \\
\text { s.t. } R_{B} \geq \frac{\bar{R}}{p_{H}} \\
p_{H}\left(q_{H}-R_{B}\right)-x_{A} \geq 0 \\
p_{H}\left(q_{H}-R_{B}\right)-x_{A} \geq p_{H}\left(q_{H}-R_{A}\right) .
\end{gathered}
$$

We solve for the interest rates supporting the proposed separating equilibrium by using the above IC and IR constraints. These constraints involve the following properties, which are important for the derivation of the results below. First, the banks objectives are linear and increasing functions of the charged loan rate. The optimum is therefore a corner solution implying that the quotes $R_{A}$ and $R_{B}$ are the maximum rates which satisfy the constraints. On the borrowers side of the market, the IR constraints exhibit the property that the $L$-type borrowers put less weight on the interest rate, because they are less concerned about their debt-service obligation than the $H$-type borrowers with higher success probability. Since the preferences toward the banks are the same for both types, this property implies that $H$-type borrowers are more likely to accept bank $B$ 's offer than the $L$-type.

Consider first the borrowers' incentive constraints. The RHS of $\mathrm{IC}_{L}$ is strictly larger than the LHS of $\mathrm{IR}_{H}$ indicating that $\mathrm{IC}_{L}$ is binding while $\mathrm{IR}_{L}$ is slack. We can therefore use $\mathrm{IC}_{L}$ to solve for $R_{A}$, which gives the following reaction function for the bank $A$ :

$$
R_{A}^{s e}\left(x_{A}\right)=R_{B}+\frac{x_{A}}{p_{L}}
$$


where the superscript se is a mnemonic for an interest rate implementing a separating equilibrium. This implies that the bank $A$ sets the interest rates just marginally below the cost the $L$-type borrower would incur should she accept the rival's offer.

To obtain the optimal interest rate for bank $B$, plug (3.1) into $\mathrm{IC}_{H}$. This implies that $\mathrm{IC}_{H}$ has to be slack so that $\mathrm{IR}_{H}$ is binding in optimum. Thus, the highest acceptable rate bank $B$ can offer to customers in the market segment $x_{A} \in\left[\underline{x}_{A}, \bar{x}_{A}\right]$ must be low enough to compensate them for the cost of visiting bank $B$ :

$$
R_{B}^{s e}\left(x_{A}\right)=q_{H}-\frac{x_{A}}{p_{H}} .
$$

Plugging (3.2) into (3.1) gives the equilibrium loan rates in each location $x_{A} \in\left[\underline{x}_{A}, \bar{x}_{A}\right]^{11}$ :

$$
\begin{aligned}
& R_{A}^{s e^{*}}\left(x_{A}\right)=q_{H}+\frac{x_{A}\left(p_{H}-p_{L}\right)}{p_{H} p_{L}}, \\
& R_{B}^{s e^{*}}\left(x_{A}\right)=q_{H}-\frac{x_{A}}{p_{H}} .
\end{aligned}
$$

The existence of a separating equilibrium depends on whether the banks can feasibly serve both types of borrowers. The participation constraints $\mathrm{PC}_{A}$ and $\mathrm{PC}_{B}$ imply that the separating equilibrium exists in locations $x_{A} \in\left[\underline{x}_{A}, \bar{x}_{A}\right]$, which satisfy $R_{A}^{s e^{*}}\left(x_{A}\right) \geq \frac{\bar{R}}{p_{L}}$ and $R_{B}^{s e^{*}}\left(x_{A}\right) \geq \frac{\bar{R}}{p_{H}}$. Solving for $x_{A}$ from the first inequality, we can obtain the lower bound, $\underline{x}_{A}$, for the locations where the bank $A$ can feasibly charge $R_{A}^{s e^{*}}\left(x_{A}\right)$ from the $L$-type customers:

$$
x_{A} \geq \frac{p_{H} \bar{R}-p_{L} Q}{p_{H}-p_{L}} \equiv \underline{x}_{A} .
$$

In a similar manner, the bank $B$ can feasibly offer contracts to the $H$-type borrowers by charging $R_{B}^{s e^{*}}\left(x_{A}\right)$ if $x_{A} \leq \bar{x}_{A}$, where

$$
Q-\bar{R} \equiv \bar{x}_{A}
$$

\footnotetext{
${ }^{11}$ Note that the $\operatorname{IR}_{L}$ condition being slack guarantees that $R_{A}^{s e^{*}}\left(x_{A}\right)<q_{L}$.
} 


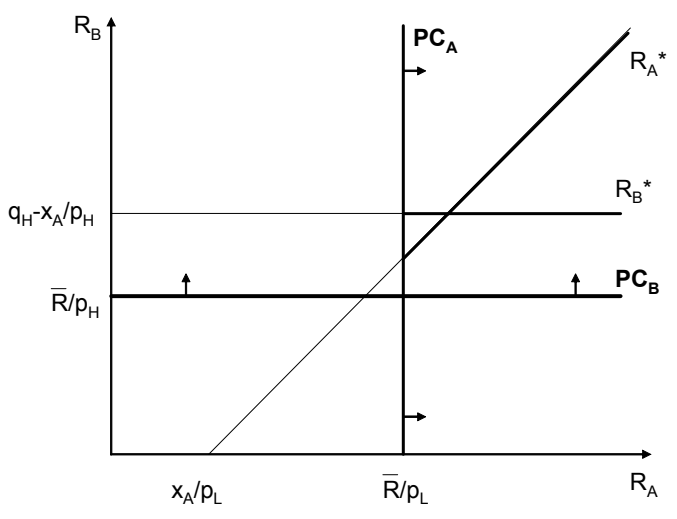

Figure 2: $\underline{x}_{A}<x_{A}<\bar{x}_{A}$

In Figure 2 the reaction function $R_{A}^{s e^{*}}\left(x_{A}\right)$ intersects the line $\frac{\bar{R}}{p_{L}}$ which illustrates bank $A$ 's participation constraint, at a point above the lowest feasible rate the bank $B$ can offer credit for $H$-type borrowers. The equilibrium interest rates can be found at the point of intersection between the lines $R_{A}^{s e^{*}}\left(x_{A}\right)$ and $R_{B}^{s e^{*}}\left(x_{A}\right)$. This is obviously strictly dominating strategy for both banks. Figures $3 \mathrm{a}$ and $3 \mathrm{~b}$, in turn, depict the cases when the cost of visiting banks is either too low or too high for the separating outcome to be feasible. In Figure 3a the reaction function $R_{A}^{s e^{*}}\left(x_{A}\right)$ intersects the line $\frac{\bar{R}}{p_{L}}$ above $R_{B}^{s e^{*}}\left(x_{A}\right)$ indicating that the rates $R_{B}^{s e^{*}}\left(x_{A}\right)$ feasible for bank $B$ are not high enough to induce bank $A$ set interest rates which would implement a separating equilibrium. Figure $3 \mathrm{~b}$ illustrates the situation where the highest rate for which the $H$ - type borrower is willing accept the offer from bank $B$ is lower than the rate bank $B$ can feasibly quote. In this case, the separating equilibrium is not feasible as there are 
no interest rates incentive compatible for each agent in the market.

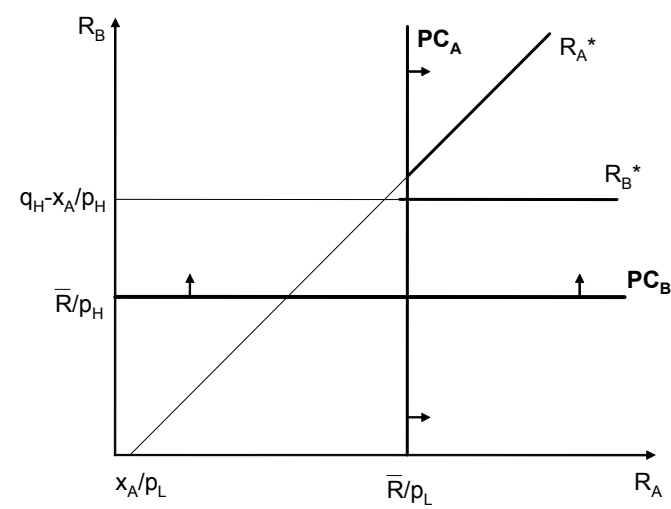

Figure 3a: $x_{A}<\underline{x}_{A}$

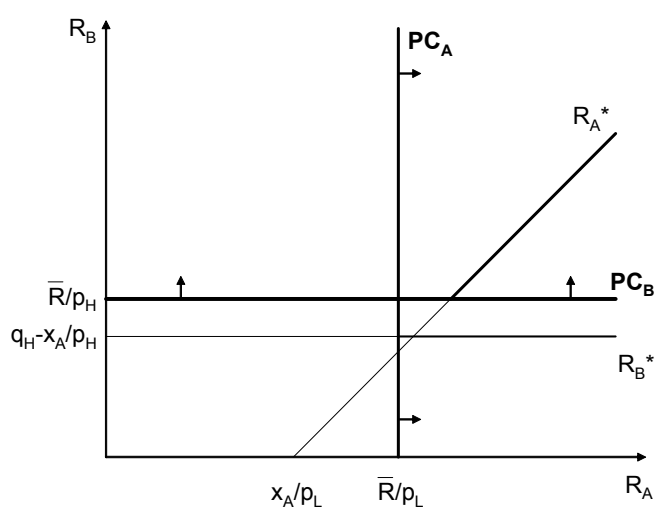

Figure $3 \mathrm{~b}: x_{A}>\bar{x}_{A}$

Lemma 1 The necessary conditions for the existence of a separating equilibrium are

$$
Q>\left(1+\frac{p_{H}-p_{L}}{p_{H}}\right) \bar{R} \quad \text { and } \quad l>\frac{2\left(p_{H} \bar{R}-p_{L} Q\right)}{p_{H}-p_{L}} \equiv \underline{l} .
$$

If (3.5) holds, there is a separating equilibrium in a market segment $x_{A} \in\left[\underline{x}_{A}, \min \left\{\bar{x}_{A}, l / 2\right\}\right]$ with $\bar{x}_{A}>\underline{x}_{A}>0$.

Proof. Observe that the set $\left[\underline{x}_{i}, \bar{x}_{i}\right]$ is non-empty if $\bar{x}_{A}>\underline{x}_{A}, \underline{x}_{A}<l / 2$ and $\bar{x}_{A}>0$. Expressions (3.3) and (3.4) imply that $\bar{x}_{A}>\underline{x}_{A}$ if

$$
\begin{aligned}
Q-\bar{R} & >\frac{p_{H} \bar{R}-p_{L} Q}{p_{H}-p_{L}} \Leftrightarrow \\
Q & >\left(1+\frac{p_{H}-p_{L}}{p_{H}}\right) \bar{R} .
\end{aligned}
$$

From (3.3) it also follows that $\underline{x}_{A}<l / 2$ when

$$
\frac{p_{H} \bar{R}-p_{L} Q}{p_{H}-p_{L}}<\frac{l}{2}
$$

Finally, $\bar{x}_{A}>0$ holds by assumption $Q>\bar{R}$. Thus, the necessary preconditions for the separating equilibrium are those expressed in (3.5). Moreover, we note that $\underline{x}_{A}>0$ because $p_{H} \bar{R}-p_{L} Q=p_{H}\left(\bar{R}-p_{L} q_{H}\right)>0 \Leftrightarrow q_{H}<\bar{R} / p_{L}$ which holds by assumption since $\bar{R} / p_{L} \geq$ $\hat{R}>q_{H}$.

Lemma 1 derives the parameter values under which the separating equilibrium is feasible. 
Provided that (3.5) holds, symmetry of the model implies that there is an identical segment $x_{B} \in\left[\underline{x}_{B}, \bar{x}_{B}\right]$ in bank B's captive markets featuring the proposed separating regime. The intuition of the result is simple. The borrowers are protected by limited liability, which means that the extent to which higher interest rates reduce the borrowers expected payoff depends on the success probability of the borrower. Obviously, the $L$-types - who have lower success rates but higher returns when successful - accept higher interest rates than the $H$-types. The cost of visiting banks, in turn, is fixed for each borrower regardless of their type. The $L$-types are therefore less likely to visit bank $B$ than the $H$-types, and consequently, the non-preferred bank might be able to serve the $H$-type clients, insofar as it can internalize the cost. The efficient separation is feasible in market segments where the cost of visiting the non-preferred bank is sufficiently large but not too high. This is because the sorting outcome is incentive compatible from the $L$-type's point of view only if the cost is significant enough. However, since the $H$-types must be compensated for the costly visit, the participation constraint of the non-preferred bank requires that this cost cannot be too large either.

\subsection{Adverse selection equilibria}

In this section we derive the market segments where some borrowers fail to receive credit, although their projects are economically viable under full information. Consider first locations $0 \leq x_{A}<\underline{x}_{A}$, where the banks cannot implement a separating equilibrium. This follows from the property that the $L$-type borrowers rather accept the rate $R_{B}^{s e^{*}}\left(x_{A}\right)$ than the offer $R_{A}^{s e^{*}}\left(x_{A}\right)$ they receive from the bank $A$. Hence, the $H$-type borrowers will not participate the market, because the banks observe that the break even rate in markets where both $L$-types and $H$ types are active equals $\hat{R}>q_{H}$. The banks therefore bid solely for the $L$-type borrowers. In such market situations the bank $A$ can employ its local monopoly power and charge a positive mark-up over the competitive loan rate $\hat{R}=\bar{R} / p_{L}$. Formally, the optimal loan rate for the bank $A$ is

$$
R_{A}^{a s}\left(x_{A}\right)=\frac{\bar{R}+x_{A}}{p_{L}}
$$

where the superscript as stands for adverse selection. The optimal strategy for the preferred bank $A$ involves an interest rate just slightly below the rate feasible for the rival.

In market segment $x_{A}>\bar{x}_{A}$ there is no rate that satisfies both the banks' participation constraints and $H$-type borrower's individual rationality constraint. The threshold $\bar{x}_{A}$ is 
derived from the participation constraint of the bank $B$ in the following manner. The strategy profile $R_{B}^{s e^{*}}\left(x_{A}\right)$ of bank $B$ is decreasing in the magnitude of the cost $x_{A}$, because the bank must internalize this cost to induce $H$-type borrowers to accept the loan offers. At the limit, $x_{A}=\bar{x}_{A}$, the corresponding rate $R_{B}^{s e^{*}}\left(\bar{x}_{A}\right)$ equals $\bar{R} / p_{H}$ implying that the bank breaks even at this location. Since $R_{B}^{s e^{*}}\left(x_{A}\right)$ is the highest rate $H$-type borrower accepts at any given location, there is no rate that satisfies both the banks' participation constraint and $H$-type borrower's individual rationality constraint in locations $x_{A}>\bar{x}_{A}$. In equilibrium, the $H$-type borrowers in that market segment will be rationed. For bank $A$ it is optimal to charge the highest rate which satisfies the constraint $\mathrm{IR}_{L}$. Thus, for $x_{A}>\bar{x}_{A}$ we have

$$
R_{A}^{a s}\left(x_{A}\right)=q_{L}
$$

The following proposition summarizes the results concerning the equilibria in the credit market

Proposition 1 Suppose that (3.5) holds. Then the equilibrium in the credit markets can be characterized as follows:

i) When $x_{A} \in\left[\underline{x}_{A}, \min \left\{\bar{x}_{A}, l / 2\right\}\right]$, the equilibrium concept is separating, where L-type borrowers will be charged according to $R_{A}^{s e^{*}}\left(x_{A}\right)$ and the $H$-type borrowers accept loan contracts from the bank $B$ with a rate equal to $R_{B}^{s e^{*}}\left(x_{A}\right)$.

ii) When $x_{A} \notin\left[\underline{x}_{A}, \min \left\{\bar{x}_{A}, l / 2\right\}\right]$, the equilibrium exhibits adverse selection: Only L-type borrowers receive finance and will be charged according to $R_{A}^{a s}\left(x_{A}\right)=\min \left\{q_{L}, \frac{\bar{R}+x_{A}}{p_{L}}\right\}$.

If condition (3.5) does not hold, the separating regime does not exist. Hence, the H-type borrowers fail to receive finance and $L$-type borrowers will be charged $R_{A}^{a s}\left(x_{A}\right)=\min \left\{q_{L}, \frac{\bar{R}+x_{A}}{p_{L}}\right\}$.

This result follows immediately from Lemma 1. In market segments where efficient separation is feasible, it is optimal for the more distant bank to quote lower rates for the $H$-type borrowers, who will accept the offers if the cost of visiting bank $B$ is not too high. The bank located closer cannot serve these borrowers, because lower rates would induce the $L$-type borrowers to accept the offers. Therefore, it is optimal for the bank $A$ to set higher rates which will be declined and accepted on behalf of the $H$-type and $L$-type borrowers, respectively. In locations where separation is not feasible, adverse selection emerges as an equilibrium outcome and therefore only $L$-type borrowers will be financed. 


\section{Competition, credit rationing and welfare}

The distance between the banks located on the two extremes of the line is given by $l$. The borrowers are randomly and evenly distributed over this line. Hence, the inverse of $l$, can be thought to represent the intensity of competition between the banks. ${ }^{12}$ To illustrate the role of bank competition on the outcomes in the credit market in terms of credit rationing and welfare let $\Phi(l)$ measure how large proportion of the markets is covered by the separating regime. This measure is defined as ${ }^{13}$

$$
\Phi(l) \equiv \frac{\min \left\{\bar{x}_{A}, l / 2\right\}-\underline{x}_{A}}{l / 2} .
$$

The next proposition examines the relationship between this measure and the degree of competition:

Proposition 2 Suppose that (3.5) holds so that $l>\underline{l}$. Then the proportion of the market featuring the separating regime, $\Phi(l)$, exhibits the following properties.

i) $\Phi^{\prime}(l)<0$ and $\Phi^{\prime \prime}(l)>0$ for $l>2 \bar{x}_{A}$. This implies that higher degree of competition increases the relative availability of credit.

ii) $\Phi^{\prime}(l)>0$ and $\Phi^{\prime \prime}(l)>0$ for $l<2 \bar{x}_{A}$. Hence, higher degree of competition decreases the relative availability of credit.

If $l \leq \underline{l}$, no separating market segment exists.

Proof. i) When $l \in\left(2 \bar{x}_{A}, \infty\right), \Phi(l)=2\left(\bar{x}_{A}-\underline{x}_{A}\right) / l$ so that $\Phi(l)$ is decreasing and convex in $l$. ii) When $l \in\left(\underline{l}, 2 \bar{x}_{A}\right], \Phi(l)=1-2 \underline{x}_{A} / l$ which clearly is increasing and convex in $l$.

The availability of credit for the $H$-type borrowers thus evolves non-monotonously along with a greater degree of competition. When competition is very intense, i.e. $l \leq \underline{l}$ defined in (3.5), adverse selection emerges as an equilibrium outcome in each location in the market and all borrowers with a high success probability will be rationed. When the banks have some market power, $H$-types receive acceptable loan offers from the more distant banks. Since these offers will be rejected by the $L$-type borrowers, efficient separation emerges as an equilibrium in these market segments. This effect, however, will be mitigated as the market power increases above a certain level, because the more distant bank cannot internalize the

\footnotetext{
${ }^{12}$ That is, higher parameter value $1 / l$ corresponds to higher degree of competition.

${ }^{13}$ I.e. what is the relative coverage of the separating segment, given by $\bar{x}_{A}-\underline{x}_{A}$, in bank $A$ 's captive markets, the lenght of which is $l / 2$.
} 
cost the $H$-types incur for conducting their business with the less preferred bank. As a result, the relative number of the $H$-types who receive credit starts decreasing.

This mechanism can be used to derive the degree of competition, which maximizes the relative number of loans in the market:

Proposition 3 The availability of credit is maximized at $l^{*}=2 \bar{x}_{A}$, which is also the welfare maximizing market structure.

Proof. The proof follows immediately from the Proposition 2.

Figure 4 illustrates the unique level for the degree of competition $l^{*}$ that maximizes the availability of credit to the borrowers. The Proposition 3 also states that $l^{*}$ is the welfare maximizing market structure, because the surplus generated by additional transactions is greater than the social cost from conducting business with a non-preferred supplier of finance.

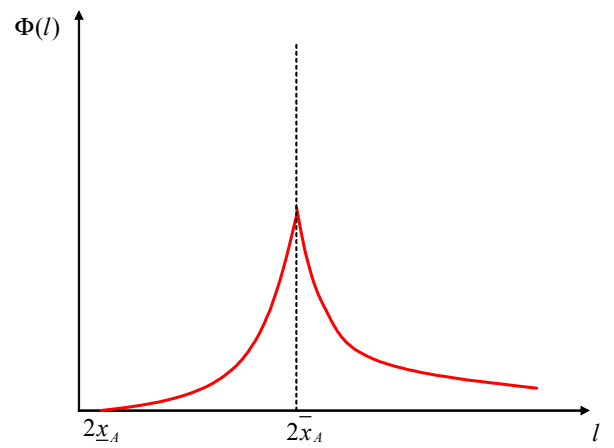

Figure 4

Since the availability of bank credit is often a necessary precondition to firm creation, our theory suggests that neither perfect competition nor very modest competition is conducive to firm creation, as the availability of credit would be maximized at an intermediate level of bank competition. This prediction is in line with the empirical study by Bonaccorsi di Patti and Dell'Ariccia (2004), who find evidence of a 'bell-shaped' relationship between bank competition and firm creation. Moreover, this pattern is the most pronounced in informational opaque industries; i.e. in sectors where the adverse selection problem is the most likely to arise. Our theory might also offer an 'indirect' explanation for the observation (e.g. Elsas, 2005) that banks operating in either very competitive or monopolized environments seem to substitute 'transaction based' lending for 'relationship based' finance. 
The analysis in this section may also offer new insight to the discussion about the effects of competition on the stability of the banking sector. A wide array of research in this issue was triggered by Keeley (1990), which claimed that the peak in bank failures in the US during the 1980's was caused by banking sector deregulation that spurred competition and reduced monopoly rents. The reason for excessive risk taking was that the reduction in the 'charter value' magnified the agency problem between bank owners and government deposit insurance fund: In the face of lower mark-ups, bank owners had greater incentive to increase upside potential via excess risk taking because limited liability and deposit insurance deadened the downside risks. ${ }^{14}$ The 'charter value' explanation, however, seems the most relevant in those cases where a bank - or a group of banks - is close to insolvency; i.e. when the stability of the financial sector is already seriously threatened. Indeed, Carletti and Hartmann (2003) conclude in their extensive survey that the claim that bank competition and banks' risk taking are generally negatively related is not necessarily robust. In our set up, banks' risk taking goes hand in hand with the extent of credit rationing, because it is the low risk borrowers - if any - who may become rationed. Hence, the higher is the availability of loans in the credit market the lower is the average default rate in the banks' loan portfolio. From this it follows that also the average credit risks (and thereby the systemic risk involved in banking) are minimized when the degree of competition satisfies the optimal level $l^{*}$.

\section{Conclusions}

The aim of this paper was to examine the adverse selection problem in an imperfectly competitive banking system and the relationship between the degree of bank competition and credit rationing. The analysis shows that efficient separation between borrowers with different success probabilities may emerge due to the underlying structure of the credit market. This result is a qualification to the existing research on adverse selection in the credit markets, where the implementation of a separating equilibrium requires socially wasteful screening practices such as collateral (Bester 1985, Besanko and Thakor 1987, Villas-Boas and Schmidt-Mohr 1994).

The result is driven by the property that imperfect competition in credit markets can facilitate sorting in certain market segments: The 'high risk - high yield' customers rather accept higher interest rates from the ex-ante preferred bank offers than pay the cost for

\footnotetext{
${ }^{14}$ Theoretical results similar to Keeley's argument were also derived by Besanko and Thakor (1993), Boot and Greenbaum (1993) and Erwards and Mishkin (1995).
} 
conducting their business in the less preferred one. The 'low risk - low yield' borrowers are more sensitive to interest rates and therefore are more likely to apply credit from the less preferred bank, provided than it can offer the contract at a sufficiently low rate. Consequently, the bank can capture the low risk customers in locations where it can internalize the cost these borrowers incur for applying credit from the non-preferred bank.

We also show that neither perfect competition nor very modest competition is conducive to the high availability of credit to new businesses. Under perfect competition, the adverse selection market failure emerges as an equilibrium and all low risk borrowers are rationed from credit. Hence, there is a unique level of competition for which the overall availability of credit is at the highest. This prediction is in line with the empirical study by Bonaccorsi di Patti and Dell'Ariccia (2004). Our theory might also explain why banks operating in either highly competitive or monopolized environments seem to substitute 'transaction based' lending for 'relationship based' finance (e.g. Elsas, 2005). Finally, we observe that because it is the low risk borrowers who may become rationed, the level of competition minimizing the credit rationing might be the market structure which fosters stability in the banking sector.

It is also worth noting that the result concerning the existence of a separating equilibrium is not limited to credit markets, as it could be generalized to other markets where asymmetric information about product or service quality generates frictions on the market. It is not implausible to think that the result applies, for instance, in labor markets where travel costs constitute a significant factor in labor mobility. In such circumstances the sorting outcome may emerge between different types of workers, because it would be more beneficial for the skilled workers to move between regions than the unskilled ones, if more distant employers offer higher wages.

\section{References}

Akerlof, G.: 1970, The market for lemons, Quarterly Journal of Economics LXXXIV, 488500.

Allen, F. and Gale, D.: 2000, Comparing Financial Systems, MIT Press, Mass.

Besanko, D. and Thakor, A.: 1993, Relationship banking, deposit insurance and bank portfolio, in C. Mayer and X. Vives (eds), Capital Markets and Financial Intermediation, Cambridge, Cambridge, UK, pp. 292-318. 
Besanko, D. and Thakor, A. V.: 1987, Collateral and rationing: Sorting equilibria in monopolistic and competitive credit markets, International Economic Review 28, 671-689.

Bester, H.: 1985, Screening vs. rationing in credit markets, American Economic Review $75,850-855$.

Bester, H.: 1987, The role of collateral in credit markets with imperfect information, European Economic Review 31, 887-899.

Bonaccorsi Di Patti, E. and Dell'Ariccia, G.: 2004, Bank competition and firm creation, Journal of Money, Credit and Banking 36, 225-251.

Boot, A. and Greenbaum, S.: 1993, Bank regulation, reputation and rents: Theory and policy implications, in C. Mayer and X. Vives (eds), Capital Markets and Financial Intermediation, Cambridge, UK.

Bouckaert, J. and Degryse, H.: 2006, Softening competition by inducing switching in credit markets, Journal of Industrial Economics 52(1).

Broecker, T.: 1990, Credit-worthiness test and interbank competition, Econometrica 58, 429452.

Caminal, R. and Matutes, C.: 2002, Market power and banking failures, International Journal of Industrial Organization 20(9), 1341-1361.

Carletti, E. and Hartmann, P.: 2003, Competition and stability: What's special about banking?, in P. Mizen (ed.), Monetary History, Exchange Rates and Financial Markets: Essays in Honour of Charles Goodhart, Edward Elgar, chapter 2, pp. 202-229.

Chen, Y.: 1997, Paying customers to switch, Journal of Economics and Management Strategy 6, 877-897.

Clemenz, G. and Ritthaler, M.: 1992, Credit markets with asymmetric information: A survey, Finnish Economic Papers 5, 12-26.

De Meza, D. and Webb, D.: 1987, Too much investment: A problem of asymmetric information, Quarterly Journal of Economics 102(2), 281-292. 
Edwards, F. and Mishkin, F.: 1995, The decline of traditional banking, implications for financial stability and regulatory policy, FED, New York, Economic Policy Review 1, 2745.

Elsas, R.: 2005, Empirical determinants of relationship lending, Journal of Financial Intermediation 14, 32-57.

Fudenberg, D. and Tirole, J.: 2000, Customer poaching and brand switching, RAND Journal of Economics 31, 634-657.

Hotelling, H.: 1929, Stability and competition, Economic Journal 39, 41-57.

Jaffee, D. M. and Russell, T.: 1976, Imperfect information, uncertainty and credit rationing, Quarterly Journal of Economics 90, 651-666.

Keeton, W. R.: 1979, Equilibrium Credit Rationing, Garland Publishing Inc., New York and London.

Kim, M., Kliger, D. and Vale, B.: 2003, Estimating switching costs; the case of banking, Journal of Financial Intermediation 12, 25-56.

Nakamura, L.: 1993, Loan screening within and outside of customer relationships, Federal Reserve Bank of Philadelphia Workin paper 93-15.

Riordan, M.: 1993, Competition and bank performance, in C. Mayer and X. Vives (eds), Capital Markets and Financial Intermediation, Cambridge University Press, Cambridge, UK, pp. 328-343.

Salop, S.: 1979, Monopolistic competition with outside goods, Bell Journal of Economics 10, 141-156.

Stiglitz, J. E. and Weiss, A.: 1981, Credit rationing in markets with imperfect information, American Economic Review 71(3), 393-410.

Villas-Boas, J. M. and Schmidt-Mohr, U.: 1999, Oligopoly with asymmetric information: Differentiation in credit markets, RAND Journal of Economics 30(3), 375-396. 